\section{ECS effects following continuous and partial reinforcement training*}

\author{
A. GRANT YOUNG and H. D. DAY \\ Louisiana State University, Baton Rouge, La. 70803
}

Thirty-two naive male albino rats were trained to leverpress for sucrose using a free-operant procedure. Half of the $S s$ were trained on a continuous-reinforcement schedule (CRF), and the other half were trained on a variable-ratio schedule (VR 2). Following acquisition, for half of $\mathrm{Ss}$ in each group, a leverpress produced footshock followed by ECS. For the remaining $S s$, a leverpress produced footshock only. Results showed that suppression of the leverpress response due to footshock was reduced by the ECS, regardless of the acquisition reinforcement schedule. Results also showed that the VR-trained Ss that received ECS failed to show the partial reinforcement effect in extinction.

The fact that electroconvulsive shock (ECS) appears to produce retrograde amnesia (RA) if administered shortly after a learning trial is well established (Lewis, 1969; Spevack \& Suboski, 1969).

This phenomenon is most generally accounted for by a hypothesis which suggests that time is required for the memory of an event to become permanently fixed (McGaugh, 1966). Presumably, following sensory input, at least two stages are involved in the fixation of the memory trace: (1) an initial stage, during which the memory trace is susceptible to disruption and (2) a later stage, where the consolidation process is complete and where the memory trace is relatively impervious to amnesic agents. Apparently, then, the massive electrical interference of ECS, if applied during the first stage, disrupts the consolidation process such that the memory trace does not become permanently fixed.

Although a number of studies (e.g., Heriot \& Coleman, 1962; Madsen \& McGaugh, 1961) have shown that a single ECS does not appear to be aversive, it has been shown that repeated ECS treatments are aversive (Hudspeth, McGaugh, \& Thompson, 1964), and Spevack \& Suboski (1969) have suggested that only those experimental procedures in which the amnesic and aversive effects of ECS have separable behavioral outcomes bear on consolidation theory. A typical procedure is to administer aversive stimulation, such as footshock, upon the emission of a learned response. The aversive stimulation results in a suppressed rate of responding; however, if ECS is administered shortly after the aversive stimulation, the result seems to be RA for this one-trial learning.

Recently, Young \& Galluscio (1970)

*This research was supported in part by a grant from the University Council of Research, LSU, to the first author. reported findings that do not support a consolidation interpretation of the effects of ECS. In that study, two groups of rats were trained to leverpress, one group on a continuous-reinforcement schedule (CRF) and the other on a fixed-ratio schedule (FR 5). Upon completion of acquisition, on pretest day, a leverpress was followed by footshock. For half the Ss in each group, footshock was followed by ECS; the other half received no ECS. All Ss were then tested during an extinction session. Results showed that during extinction the CRF group receiving ECS following footshock made significantly more responses than did the CRF group receiving footshock only. However, both FR 5 groups showed significantly suppressed response rates, not significantly different from each other, although one group had received footshock plus ECS and the other group had received footshock only. Thus, ECS did not eliminate suppression of response rates following training on a FR schedule.

These findings are in agreement with those reported earlier by Adams, Peacock, \& Hamrick (1967). Adams et al suggested that, rather than producing RA for aversive stimulation, ECS produces disinhibition in that it removes the inhibition of responding. Since disinhibition does not show if the response rate is high, the effect of ECS following aversive stimulation should be different for Ss trained on a FR schedule, which generates high response rates, than for $S s$ trained on a CRF schedule which generates a lower response rate.

To determine whether response rate is a critical variable, Young \& Galluscio (in press) replicated their first experiment; however, in the second experiment a discrete-trial procedure was used to control response rates. With this technique the acquisition-response rate for FR-trained Ss was significantly lower than that for CRF-trained Ss, and results showed that ECS apparently produced RA in both groups, which suggests that the effect of ECS may be a function of acquisition-response rates. $A$ second finding of the Young and Galluscio studies was the failure of FR-trained Ss to show the partial-reinforcement effect (PRE)-the increased resistance to extinction shown by Ss trained on a partial-reinforcement schedule.

The present study was designed to determine (1) whether or not effect of ECS is a function of acquisition-response rate when Ss are trained on a variable-ratio (VR) schedule and (2) whether or not VR-trained Ss will show the PRE following ECS treatment.

\section{SUBJECTS}

The Ss were 32 naive male albino rats, $175.200 \mathrm{~g}$ in weight at the start of the experiment.

\section{APPARATUS}

The apparatus consisted of two identical Scientific Prototype operant chambers, each enclosed in a sound-insulated ventilated cubicle. Each operant chamber had a grid floor, and fitted on the end wall was a retractable lever and a liquid dipper that dispensed $.01 \mathrm{ml}$ of a $40 \%$ sucrose solution used as reinforcement. All E-controlled events were operated by an electronic programming device.

\section{PROCEDURE}

The Ss were selected randomly from the LSU colony, were placed in individual cages, and kept on an ad lib food and water schedule for 4 days, after which Ss were placed on a food-deprivation schedule of $10 \mathrm{~g}$ Purina chow every $24 \mathrm{~h}$. Water was available in the cages at all times, and Ss were fed approximately $10 \mathrm{~min}$ after each experimental session.

From the 5 th to the 9 th day, Ss were handled in pairs for $5 \mathrm{~min}$ daily, and on the 10 th day, Ss began magazine training on a VI 30-sec schedule. Experimental periods consisted of 20 presentations of the dipper and were continued for 4 days. On the 14 th day all Ss were conditioned to leverpress, and on the following day were allowed to make 100 reinforced responses. On the 16th day, Ss were divided randomly into two groups, VR and $C R$, and began acquisition training. For the $\mathrm{VR}$ group, acquisition was under a VR 2 reinforcement schedule, and for the $C R$ group, acquisition was under a CRF schedule. All Ss were given 100 leverpresses daily for 10 days, using a free-operant procedure.

On the day following completion of acquisition, each group was subdivided randomly, resulting in the following four 
Table 1

Mean Number of Leverpresses in Extinction

\begin{tabular}{lcc}
\hline Group & $\begin{array}{c}\text { Mean Responses } \\
\text { First Minute }\end{array}$ & $\begin{array}{c}\text { Total Mean } \\
\text { Responses }\end{array}$ \\
\hline VR (ECS) & 35.75 & 126.75 \\
CR (ECS) & 26.75 & 117.87 \\
VR (SO) & 5.26 & 82.62 \\
CR (SO) & 0.75 & 37.00 \\
\hline
\end{tabular}

Table 2

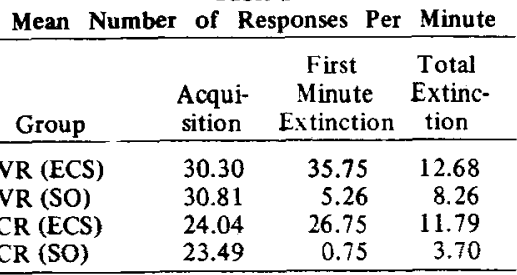

groups (eight Ss per group): CR(ECS), VR(ECS), CR(SO), and VR(SO). Groups CR(ECS) and VR(ECS): On treatment day, Ss in these two groups were fitted with a harness. Fine wire from an ECS source, which entered the operant chamber from the top, was connected to the harness and from the harness to microalligator clips which attached to S's ears. The harness arrangement permitted complete freedom of movement to all parts of the operant chamber. The first leverpress produced a $9 \cdot \mathrm{mA}$ footshock of $2 \cdot \mathrm{sec}$ duration, delivered through the grid floor, and the lever retracted. The offset of footshock initiated the onset of a $50-\mathrm{mA}, 500-\mathrm{msec}$ ECS delivered through the ear-clip electrodes. Groups $\mathrm{CR}(\mathrm{SO})$ and $\mathrm{VR}(\mathrm{SO})$ : For Ss in these two groups, treatment was identical to that of the two groups above, except that footshock was not followed by ECS.

On the day following treatment, Ss were subjected to a 10-min extinction session. During extinction the stimulus conditions were the same as during acquisition, except that the dipper was inoperative.

\section{RESULTS}

The total number of responses made by each $S$ in extinction was recorded at the end of the first minute and at the end of the 10-min period. The results for both time periods showed that more responses were made by Group VR(ECS), followed in order by Groups CR(ECS), VR(SO), and CR(SO). The data for the full $10 \mathrm{~min}$ of extinction were subjected to an analysis of variance, which showed that the main effect of treatment was significant beyond the .001 level and the main effect of reinforcement schedule was significant beyond the .05 level. The Treatment by
Schedule interaction did not reach significance, $F(1,28)=2.90$. Group comparisons ( $t$ tests) showed that the following comparisons were significant beyond the .01 level: $\mathrm{CR}(\mathrm{ECS})$ vs $\mathrm{CR}(\mathrm{SO})$, VR(ECS) vs VR(SO), VR(SO) vs CR(SO). The comparison VR(ECS) vs CR(ECS) was not significant $(t<1.00)$. The total number of responses made by each $S$ during the first minute of extinction was subjected to the same statistical analysis, which showed that only the treatment effect was significant $(p<.001)$. Group comparisons (t tests) showed that VR(ECS) vs VR(SO) and CR(ECS) vs $\mathrm{CR}(\mathrm{SO})$ both were significant beyond the .01 level. The mean number of responses in extinction for all groups is shown in Table 1.

Table 2 shows group mean response rates on the last 2 days of acquisition, on the first minute of extinction, and for the full 10-min extinction period. Although there were no differences in acquisition response rates for the SO and ECS groups, the CR-trained Ss were significantly slower than the VR-trained Ss $(\mathrm{p}<.05$, Mann-Whitney U). A comparison of response rates for the first minute on test day and for the full 10-min test period showed Group VR(SO) significantly slower than Group VR(ECS), and Group CR(SO) significantly slower than Group CR(ECS) $(\mathrm{p}<.01$, Mann-Whitney U). DISCUSSION

The finding that the CR(ECS) group made significantly more responses in extinction than did the CR(SO) group agrees with earlier findings.

A critical finding of this study is that, for VR-trained $S s$, the immediate administration of ECS following footshock eliminated or reduced suppression of responding. Although these results support a consolidation of memory hypothesis, it is not clear that they are in agreement with the findings of Young \& Galluscio (1970). In that study ECS failed to eliminate suppression of responding for FR Ss trained in a free-operant situation, and it was suggested that this might be due to the higher acquisition-response rate shown by the FR-trained Ss. It is still possible that acquisition-response rate may be a critical variable in determining the effects of ECS because in the present study, although the acquisition-response rate was higher for the VR-trained Ss than for the CR-trained Ss, it, nevertheless, was considerably lower than the acquisition response rates reported by Young \& Galluscio (1970) for their FR-trained Ss.
A second critical finding of this study is the failure of the VR(ECS) group to show the PRE when compared with the CR(ECS) group. Although the VR(ECS) group made more responses in extinction than did the CR(ECS) group, the difference did not approach statistical significance and, in fact, the difference between the means was quite small. This finding, that the administration of ECS causes the loss of the PRE, is in agreement with the findings of Young \& Galluscio (1970). It would not appear that acquisition response rate is a critical variable, however, because they reported the loss of the PRE for FR-trained Ss, regardless of whether acquisition-response rate was lower or higher than CR-trained Ss.

If the PRE is caused by some type of conditioned emotional response, such as frustration (Amsel, 1958), these findings suggest that the administration of ECS either neutralizes the emotional response or interferes with the previously established connection between the emotional response and the stimuli of the experimental environment.

\section{REFERENCES}

ADAMS, H. E., PEACOCK, L. J., \& HAMRICK, D. D. ECS and one-trial learning: Retrograde amnesia or disinhibition? Physiology \& Behavior, 1967, 2, 435-437.

AMSEL, A. The role of frustrative nonreward in noncontinuous reward situations. Psychological Bulletin, 1958, 55, 102-119.

HERIOT, J. T., \& COLEMAN, P. D. The effect of electroconvulsive shock on retention of a modified "one-trial" conditioned avoidance. Journal of Comparative \& Physiological Psychology, 1962, 55, 1082-1084.

HUDSPETH, W. J., MCGAUGH, J. L., \& THOMPSON, C. W. Aversive and amnesic effects of electroconvulsive shock. Journal of Comparative \& Physiological Psychology, $1964,57,61-64$.

LEWIS, D. J. Sources of experimental amnesia. Psychological Review, 1969, 76, 461-472.

MADSEN, M. C., \& McGAUGH, J. L. The effect of ECS on one-trial avoidance learning. Journal of Comparative \& Physiological Psychology, $1961,54,522-523$.

McGAUGH, J. L. Time-dependent processes in memory storage. Science, 1966, 153, 1351-1358.

SPEVACK, A. A., \& SUBOSKI, M. D. Retrograde effects of electroconvulsive shock on learned responses. Psychological Bulletin, 1969, 72, 66-76.

YOUNG, A. G., \& GALLUSCIO, E. H. Failure of ECS to produce retrograde amnesia following partial reinforcement training. Psychonomic Science, 1970, 18, 175-176.

YOUNG, A. G., \& GALLUSCIO, E. H. Effect of ECS on one-trial learning following continuous and partial reinforcement training. Psychonomic Science, 1970, 21, 43-44. 